\title{
Antimicrobial Activity of Common Mouthwash Solutions on Multidrug-Resistance Bacterial Biofilms
}

\author{
Majed M. Masadeh ${ }^{\mathrm{a}, \mathrm{c}}$, Shadi F. Gharaibeh ${ }^{\mathrm{b}}$, Karem H. Alzoubi ${ }^{\mathrm{b}}$, \\ Sayer I. Al-Azzam ${ }^{\mathrm{b}}$, Wasfi M. Obeidat ${ }^{\mathrm{a}}$
}

\begin{abstract}
Background: Periodontal bacteria occur in both planktonic and biofilm forms. While poor oral hygiene leads to accumulation of bacteria, reducing these microbes is the first step toward good oral hygiene. This is usually achieved through the use of mouthwash solutions. However, the exact antibacterial activity of mouthwash solution, especially when bacteria form biofilms, is yet to be determined. In this study, we evaluated the antibacterial activity of common mouthwash solutions against standard bacteria in their planktonic and biofilm states.
\end{abstract}

Methods: Standard bacterial strains were cultured, and biofilm were formrd. Thereafter, using standard method for determination of minimum inhibitory concentrations (MIC) values of various mouthwash solutions were determined.

Results: Results show that common mouthwash solutions have variable antibacterial activity depending on their major active components. Only mouthwash solutions containing chlorohexidine gluconate or cetylpyridinum chloride exhibited activity against majority, but not all tested bacterial strains in their biofilm state. Additionally, bacteria are generally less susceptible to all mouthwash solutions in their biofilm as compared to planktonic state.

Conclusions: While mouthwash solutions have variable antibacterial activity, bacteria in their biofilm state pose a challenge to dental hygiene/care where bacteria become not susceptible to majority of available mouthwash solutions.

Keywords: Mouthwash; Antimicrobial; Biofilm; Planktonic

\footnotetext{
Manuscript accepted for publication July 10, 2013

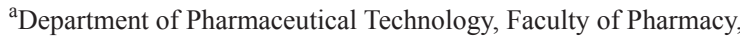
Jordan University of Science and Technology, Irbid 22110, Jordan ${ }^{b}$ Department of Clinical Pharmacy, Faculty of Pharmacy, Jordan University of Science and Technology, Irbid 22110, Jordan ${ }^{\mathrm{c}}$ Corresponding author: Majed M. Masadeh, Faculty of Pharmacy, Jordan university of Science and Technology, Irbid 22110, Jordan. Email: mmmasadeh@just.edu.jo
}

doi: http://dx.doi.org/10.4021/jocmr1535w

\section{Introduction}

When unicellular organisms come together forming a community and attached to a solid surface then encased in an exo-polysaccharide matrix, bacterial biofilms are formed [13]. These biofilms can be made up of single or multiple bacterial species. As periodontal biofilms are more resistance to antibiotics than planktonic cells, their control pauses a real problem, and requires special care of mouth hygiene [4, 5].

More than three hundred known species of bacteria are considered as oral flora [6]. They include species in both panktonic and biofilm states [1-2]. Poor oral hygiene causes accumulation of metabolites of these oral floras, through which dental caries, gingivitis, and periodontitis will be induced [7-9]. Reducing these microbes is the first step in the endodontic therapy as it enhances the normal healing process of the periodontal tissues [10].

Mouthwash solutions are aimed at ensuring sufficient oral hygiene. Its ease of use in addition to the significant ability to reduce dental plaque formation, made mouthwashes a reasonable method to limit gingivitis and periodontitis $[4,11-13]$. However, the consumer faces a wide range of options of mouthwash solutions that differ in their deodorant, analgesic or astringent property and antimicrobial effectiveness [14-16]. This different effect on oral flora in addition to the differences in the susceptibility to antimicrobials in mouthwash solutions between biofilms and planktonic cells highlights the importance of screening oral antimicrobial formulations in an effort to produce more predictive of clinical activity $[5,15,17]$. In this study, we evaluated the effect of different mouthwash solutions on variety of bacteria both in their biofilm and planktonic states.

\section{Materials and Methods}

\section{Mouthwash solutions}

Mouthwash solutions were obtained from the local market. Table 1 shows the active ingredients, and $\mathrm{pH}$ of each of the mouthwash solutions tested. 
Table 1. Active Ingredients and $\mathrm{pH}$ of Mouthwash Solutions

\begin{tabular}{|c|c|c|}
\hline Mouthwash & Active ingredients & pH \\
\hline A & Cetylpyridinium chloride $0.05 \% \mathrm{w} / \mathrm{w}$, sodium fluoride $0.05 \% \mathrm{w} / \mathrm{w}$ & 6.3 \\
\hline B & Sodium bicarbonate $2 \% \mathrm{w} / \mathrm{v}$, sodium benzoate & 8.4 \\
\hline $\mathrm{C}$ & Chlorhxidine gluconate $0.2 \% \mathrm{w} / \mathrm{v}$ & 3.9 \\
\hline $\mathrm{D}$ & $\begin{array}{l}\text { Potassium aluminum sulphate } 0.1 \% \text {, Chlorhexidine gluconate } 0.1 \% \mathrm{w} / \mathrm{v} \text {, ethanol }(96 \%) 10 \% \text {, } \\
\text { Menthol crystals } 0.045 \%\end{array}$ & 1.9 \\
\hline $\mathrm{E}$ & Chlorhexidine gluconate $0.2 \% \mathrm{w} / \mathrm{v}$, ethanol $7.9 \%$ & 5.7 \\
\hline $\mathrm{F}$ & Chlorhexidine gluconate $0.2 \% \mathrm{w} / \mathrm{v}$ & 5.4 \\
\hline G & Hexetidine $0.1 \% \mathrm{w} / \mathrm{v}$ & 3.1 \\
\hline $\mathrm{H}$ & Povidone -iodine $1 \% \mathrm{w} / \mathrm{v}$ & 2.5 \\
\hline I & Eucalyptol $0.092 \%$, Menthol $0.042 \%$, Methylsalicylate $0.060 \%$, thymol $0.064 \%$ & 4.1 \\
\hline
\end{tabular}

\section{Bacterial strains and media}

The following bacterial strains were purchased and used in the study: Escherichia coli (ATCC 25922), Enterococcus faecalis (ATCC 19433), Staphylococcus aureus (ATCC 29213), Methicillin Resistans Staphylococcus Aureus MRSA (ATCC 43300), Pseudomonas aeruginosa (ATCC 27853), Staphylococcus epidermidis (ATCC 12228), Klebsiella pneumoniae (ATCC 13883), Streptococcus pyogenes (ATCC 19615), Proteus mirabilis (ATCC 12453), and Acinitobacter baumanni (ATCC 19606). All strains were stored in trypticase-soy broth with $20 \%$ glycerol (BBL Microbiology Systems, Cockeysville, Md., USA) at $-70{ }^{\circ} \mathrm{C}$ in a deep freezer until ready for susceptibility testing. They were thawed and passed 3 times to assure purity and viability before each experiment.

\section{Biofilm formation, harvesting, and screening}

Biofilm cells were performed as described by [18] under standardized aseptic conditions. Briefly, $100 \mu \mathrm{L}$ of bacterial suspension from each strain was cultivated in polypropylene tubes containing $2 \mathrm{~mL}$ of Trypticase Soy Broth (TSB) supplemented with $1 \%$ glucose for 48 hours at $37^{\circ} \mathrm{C}$. Culture media was refreshed after 24 hours of incubation. After $48 \mathrm{hr}$ of incubation, biofilm cells were harvested by discarding the culture media and washing the tubes three times with phosphate buffer saline (PBS, pH 7.2), to remove non adherent bacteria, and then the adhered cells were harvested by vortex and centrifugation. The pellet was suspended in PBS ( $\mathrm{pH} 7.2$ ) to achieve the desired turbidity (comparable to a 0.5 McFarland turbidity standard). Screening for biofilms for- mation was achieved as previously described in [19]. Briefly, after being emptied from their content, culture tubes were stained with trypan blue or safranin. Biofilms were judged by the appearance of a visible film lined the walls of the tube. Observations were carried out by three independent observers. Biofilms were scored as absent (score 0), weak (score 1), moderate (score 2), or strong (score 3 ). The average scores were used.

\section{Determination of minimum inhibitory concentrations (MIC) values}

The MIC values of both $S$. aureus and $P$. aeruginosa planktonic and biofilm cells were tested against selected antibiotics, MIC were determined by using broth macrodilution method according to NCCLS [20]. Briefly, $100 \mu \mathrm{L}$ of adjusted bacterial suspensions equivalent to $0.5 \mathrm{McF}$ arland standard were added to a 2-fold serial dilutions of selected antibiotics diluted in Mueller Hinton broth. The results were observed after 24 hours of incubation at $37{ }^{\circ} \mathrm{C}$. The lowest concentration of antibiotic needed to inhibit microbial growth compared to control culture was defined as MIC. Tests were performed in triplicate for each antibiotic.

\section{Results}

The MIC values of tested mouthwash solutions against bacterial planktonic strains are shown in Table 2. Mouthwash A has antimicrobial activity against all strains except $P$. aeruginosa and $K$. pneumoniae. Mouthwashes B, C, D, and E, have activity against all strains used in the study. In addi- 


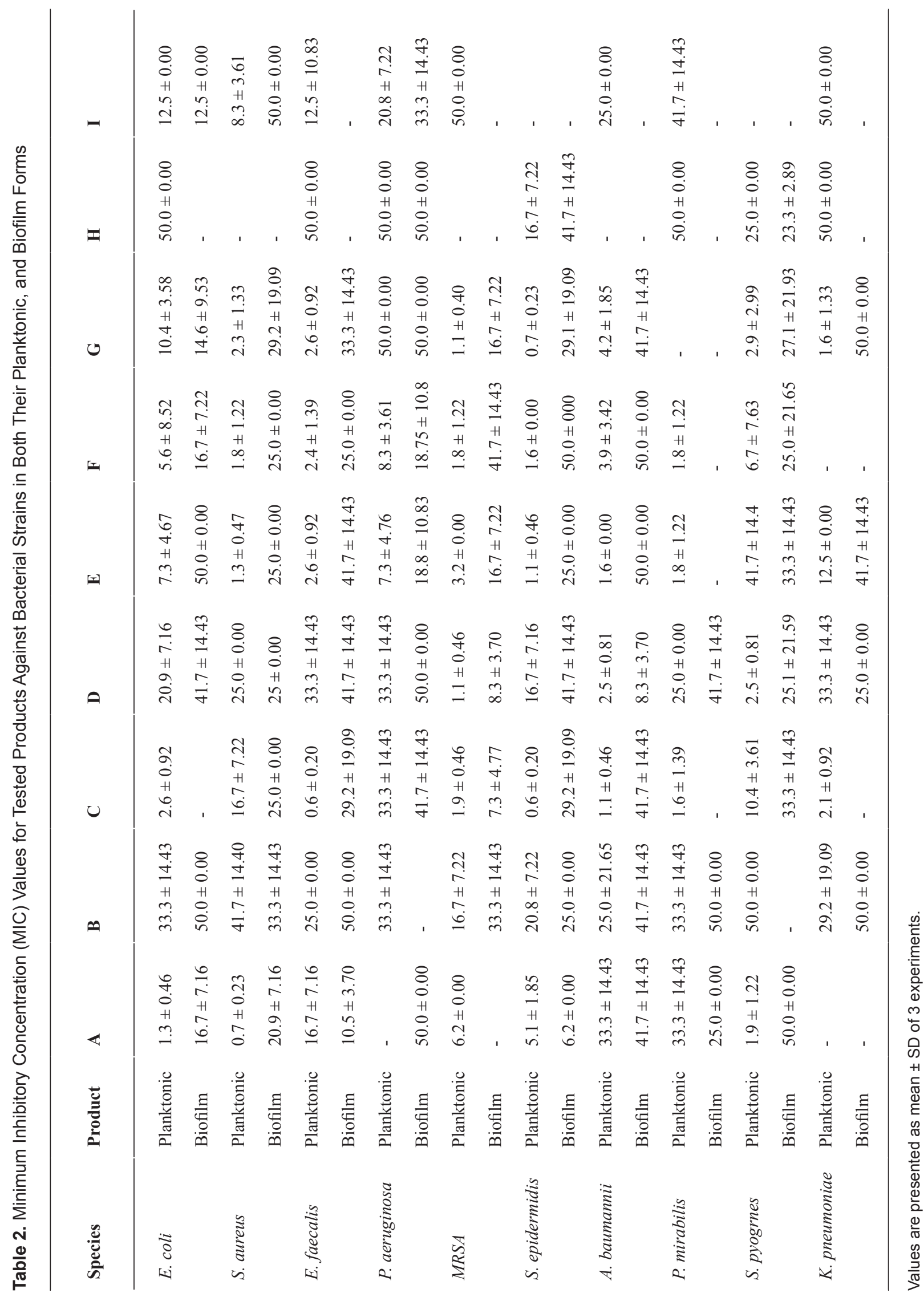


tion, mouthwash F exhibits high activity (low MIC values) against all strains except $K$. pneumoniae. However, mouthwashes $H, G$, and I show activity against some strains, but no activity against others. Although mouthwash $\mathrm{B}$ is active against all strains, its MIC values are larger than those for mouthwashes C, D, and E for almost all strains. Moreover, mouthwash B shows lower activity (larger MIC values) except for K. pneumoniae when compared with mouthwash F. This indicates that mouthwash $\mathrm{B}$ exhibits less activity than C, D, E, and F. Mouthwash I has some activity against all bacterial strains except $S$. epidermidis, $S$. pyogenes. Moreover, it has low activity (MIC values $>25 \%$ ) against $M R S A$, $K$. pneumoniae, and A. baumannii. Mouthwash $\mathrm{H}$ exhibits little activity (no activity or high MIC values) against planktonic bacterial strains.

Table 2 also lists MIC values for tested mouthwashes against bacterial biofilm strains. The results show that the MIC values of tested mouthwashes against biofilm strains are greater compared with the planktonic strains. Among the tested mouthwashes, A, C, D, E, and F exhibit MIC values for most of the tested bacterial strains. However, mouthwashes B, H, and I show either higher MIC values or no activity for almost all strains.

\section{Discussion}

Mouthwash solutions usually encompass antimicrobial activity that ensures their work in eliminating harmful periodontal bacteria, which aids in preventing future dental carries, gingivitis and periodontitis [4, 11-13]. In here, we showed that mouthwash solutions are generally less effective against bacteria in their biofilm compared to planktonic forms. Additionally, common mouthwash solutions were shown to possess variable antibacterial activity against bacteria in their biofilm state depending on their major active components.

Bacterial biofilms formation is associated with poor dental hygiene that provides better environment for biofilms formation, thus, rendering oral bacteria less susceptible to mouthwash or similar antiseptic formulation [5, 15, 17]. Therefore, keeping good oral hygiene, which is expected to help in avoiding the biofilms formation, is recommended to ensure maintaining susceptibility of oral bacteria to mouthwash and other dental hygiene procedures.

Results of this study show that mouthwash solution possesses variable antibacterial activity depending on their chemical composition. For example, mouthwash solutions containing the antiseptics chlorhexidine are effective on most oral bacterial strains. This correlates with previous studies and is related to chlorohexidine's mode of action as it works on different sites of the bacteria [21, 22]. Additionally, mouthwash solutions containing sodium bicarbonate $2 \%$ were shown to be effective against most of the tested bacterial strains, which is in agreement of previous studies $[23,24]$

On the other hand, mouthwash solutions containing other ingredients such as cetylpyridinium chloride, sodium fluoride, hexetidine, povidone-iodine, eucalyptol, menthol, methylsalicylate, and thymol showed activity against some bacterial strains, but not others. For example, cetylpyridinium chloride $(0.05 \%)$ mouthwash was shown to possess antimicrobial activity against all tested bacterial strains except $P$. aeruginosa and $K$. pneumoniae. In fact, cetylpyridinum chloride is a quaternary ammonium compound known for its use as a cationic surface active agent that has antibacterial activity $[15,25,26]$. Moreover, the MIC values for cetylpyridinium chloride $(0.05 \%)$ mouthwash suggest that it has high activity against $S$. aureus. This is in agreement with previously published work on cetylpyridinium chloride products [27].

The eucalyptol mouthwash has some activity against all bacterial strains except $S$. epidermidis, $S$. pyogenes. Moreover, It has low activity (MIC values $>25 \%$ ) against $M R S A$, $K$. pneumoniae, and A. baumannii. This mouthwash contains active ingredients of eucalyptol, menthol, methylsalicylate, and thymol. Eucalyptol, which is present in the essential oil of Eucalyptus, has been reported to posses some antibacterial activity against $S$. aureus and E.coli [28-30]. However, it has limited activity against other bacterial strains [28-30]. In addition, menthol and thymol were reported to have limited antibacterial activity [31].

The hexitidine $0.1 \%$ mouthwash has high activity against all strains except $P$. mirabilis. Upon comparison to mouthwashes that contains chlorhexidine as the main active ingredient, hexetidine $0.1 \%$ mouthwash exhibited less antibacterial activity against almost all strains. This is in agreement with work reported by Aznita et al [32].

Results of the current study show that the MIC values of tested products against biofilm strains are greater compared with the planktonic strains. This is in agreement with what is known about biofilm resistance to anti microbial agents $[4,5]$. Several mechanisms for increased antimicrobial resistance of the biofilms have been suggested $[1,2,5]$. It is also reported that multiple resistance mechanisms can be working in a single biofilm community [33]. Among the tested mouthwash solutions, containing chlorohexidine gluconate or cetylpyridinum chloride exhibited certain antibacterial activity against majority of tested biofilm bacterial strains. However, other mouthwashes limited or no antibacterial activity for most strains. This is in agreement with previous studies showing that cetylpyridinum chloride and chlorohexidine gluconate have activity against bacterial strains in their biofilm state [34, 35].

Collectively, it is been shown that bacteria in their biofilm state is less susceptible to mouth wash solutions. Only mouthwash solutions containing chlorohexidine gluconate or cetylpyridinum chloride exhibited activity against major- 
ity, but not all tested bacterial strains in their biofilm state.

\section{Conflict of Interest}

The authors declare no conflict of interest.

\section{References}

1. Huang R, Li M, Gregory RL. Bacterial interactions in dental biofilm. Virulence. 2011;2(5):435-444.

2. Hojo K, Nagaoka S, Ohshima T, Maeda N. Bacterial interactions in dental biofilm development. J Dent Res. 2009;88(11):982-990.

3. Arciola CR, Campoccia D, Speziale P, Montanaro L, Costerton JW. Biofilm formation in Staphylococcus implant infections. A review of molecular mechanisms and implications for biofilm-resistant materials. Biomaterials. 2012;33(26):5967-5982.

4. Pires JR, Rossa Junior C, Pizzolitto AC. In vitro antimicrobial efficiency of a mouthwash containing triclosan/gantrez and sodium bicarbonate. Braz Oral Res. 2007;21(4):342-347.

5. Hannig C, Basche S, Burghardt T, Al-Ahmad A, Hannig $\mathrm{M}$. Influence of a mouthwash containing hydroxyapatite microclusters on bacterial adherence in situ. Clin Oral Investig. 2013;17(3):805-814.

6. Parahitiyawa NB, Scully C, Leung WK, Yam WC, Jin LJ, Samaranayake LP. Exploring the oral bacterial flora: current status and future directions. Oral Dis. 2010;16(2):136-145.

7. Hughes FJ, McNab R. Oral malodour--a review. Arch Oral Biol. 2008;53 (Suppl 1):S1-7.

8. Brook I. Microbiology and management of periodontal infections. Gen Dent. 2003;51(5):424-428.

9. Sullivan R, Santarpia P, Lavender S, Gittins E, Liu Z, Anderson MH, He J, et al. Clinical efficacy of a specifically targeted antimicrobial peptide mouth rinse: targeted elimination of Streptococcus mutans and prevention of demineralization. Caries Res. 2011;45(5):415-428.

10. Abbott PV, Salgado JC. Strategies for the endodontic management of concurrent endodontic and periodontal diseases. Aust Dent J. 2009;54(Suppl 1):S70-85.

11. Mouthrinses and periodontal disease. Int Dent $\mathrm{J}$. 2002;52(5):346-352.

12. Andrade Acevedo R, Machon L, Chavez N. Effectiveness of a mouthwash containing Triclosan and Gantrez in the reduction of biofilm and gingivitis: a clinical pilot study. J Contemp Dent Pract. 2009;10(6):E033-040.

13. Haffajee AD, Yaskell T, Socransky SS. Antimicrobial effectiveness of an herbal mouthrinse compared with an essential oil and a chlorhexidine mouthrinse. J Am Dent Assoc. 2008;139(5):606-611.
14. Lim KS, Kam PC. Chlorhexidine--pharmacology and clinical applications. Anaesth Intensive Care. 2008;36(4):502-512.

15. Williams MI. The antibacterial and antiplaque effectiveness of mouthwashes containing cetylpyridinium chloride with and without alcohol in improving gingival health. J Clin Dent. 2011;22(6):179-182.

16. Gagari E, Kabani S. Adverse effects of mouthwash use. A review. Oral Surg Oral Med Oral Pathol Oral Radiol Endod. 1995;80(4):432-439.

17. Moeintaghavi A, Arab H, Khajekaramodini M, Hosseini R, Danesteh H, Niknami H. In vitro antimicrobial comparison of chlorhexidine, persica mouthwash and miswak extract. J Contemp Dent Pract. 2012;13(2):147152.

18. Cernohorska L, Votava M. Antibiotic synergy against biofilm-forming Pseudomonas aeruginosa. Folia Microbiol (Praha). 2008;53(1):57-60.

19. Christensen GD, Simpson WA, Younger JJ, Baddour LM, Barrett FF, Melton DM, Beachey EH. Adherence of coagulase-negative staphylococci to plastic tissue culture plates: a quantitative model for the adherence of staphylococci to medical devices. J Clin Microbiol. 1985;22(6):996-1006.

20. National Committee for Clinical Laboratory Standards. MIC testing supplement tables, Villanova, NCCLS, M00-S13(M). 2003.

21. Baradari AG, Khezri HD, Arabi S. Comparison of antibacterial effects of oral rinses chlorhexidine and herbal mouth wash in patients admitted to intensive care unit. Bratisl Lek Listy. 2012;113(9):556-560.

22. Russell AD, Day MJ. Antibacterial activity of chlorhexidine. J Hosp Infect. 1993;25(4):229-238.

23. Drake D. Antibacterial activity of baking soda. Compend Contin Educ Dent Suppl. 1997;18(21):S17-21;quiz S46.

24. Ko KY, Mendonca AF, Ahn DU. Influence of zinc, sodium bicarbonate, and citric acid on the antibacterial activity of ovotransferrin against Escherichia coli O157:H7 and Listeria monocytogenes in model systems and ham. Poult Sci. 2008;87(12):2660-2670.

25. Schaeffer LM, Szewczyk G, Nesta J, Vandeven M, DuThumm L, Williams MI, Arvanitidou E. In vitro antibacterial efficacy of cetylpyridinium chloride-containing mouthwashes. J Clin Dent. 2011;22(6):183-186.

26. Witt J, Ramji N, Gibb R, Dunavent J, Flood J, Barnes J. Antibacterial and antiplaque effects of a novel, alcoholfree oral rinse with cetylpyridinium chloride. J Contemp Dent Pract. 2005;6(1):1-9.

27. Watanabe E, Tanomaru JM, Nascimento AP, MatobaJunior F, Tanomaru-Filho M, Yoko Ito I. Determination of the maximum inhibitory dilution of cetylpyridinium chloride-based mouthwashes against Staphylococcus aureus: an in vitro study. J Appl Oral Sci. 2008;16(4):275- 
279.

28. Ashour HM. Antibacterial, antifungal, and anticancer activities of volatile oils and extracts from stems, leaves, and flowers of Eucalyptus sideroxylon and Eucalyptus torquata. Cancer Biol Ther. 2008;7(3):399-403.

29. Mulyaningsih S, Sporer F, Reichling J, Wink M. Antibacterial activity of essential oils from Eucalyptus and of selected components against multidrug-resistant bacterial pathogens. Pharm Biol. 2011;49(9):893-899.

30. Elaissi A, Rouis Z, Salem NA, Mabrouk S, ben Salem Y, Salah KB, Aouni M, et al. Chemical composition of 8 eucalyptus species' essential oils and the evaluation of their antibacterial, antifungal and antiviral activities. BMC Complement Altern Med. 2012;12:81.

31. Trombetta D, Castelli F, Sarpietro MG, Venuti V, Cristani M, Daniele C, Saija A, et al. Mechanisms of antibacterial action of three monoterpenes. Antimicrob Agents Chemother. 2005;49(6):2474-2478.
32. Aznita, H, Z Zainal-Abidin, E Aznan, and M Razi. The Effectiveness of Chlorhexidine, Hexetidine and Eugenia caryophyllus Extracts in Commercialized Oral Rinses to Reduce Dental Plaque Microbes. Research Journal of Biological Sciences. 2009;4(6):p. 716-719.

33. Mah TF, O'Toole GA. Mechanisms of biofilm resistance to antimicrobial agents. Trends Microbiol. 2001;9(1):3439.

34. Kara D, Luppens SB, Cate JM. Differences between single- and dual-species biofilms of Streptococcus mutans and Veillonella parvula in growth, acidogenicity and susceptibility to chlorhexidine. Eur J Oral Sci. 2006;114(1):58-63.

35. Sena NT, Gomes BP, Vianna ME, Berber VB, Zaia AA, Ferraz CC, Souza-Filho FJ. In vitro antimicrobial activity of sodium hypochlorite and chlorhexidine against selected single-species biofilms. Int Endod J. 2006;39(11):878-885. 